\title{
Reduction of Torque Ripples in PMSM using Fuzzy Controlled based Driving Converter
}

\author{
Dr J Viswanatha Rao ${ }^{a}$, Mr G.Lakshminarayana ${ }^{\mathrm{b}}$ and Dr D.Obulesu ${ }^{\mathrm{c}}$ \\ aProfessor, EEE Department, VNRVJIET, viswanatharao_j@vnrvjiet.in \\ ${ }^{\mathbf{b}}$ Asst. Professor, EEE Department, VNRVJIET,lakshminarayana_g@ vnrvjiet.in \\ 'Associate Professor,CVR College of Engineering, obuleshdakka@ rediffmail.com
}

Article History: Received: 10 November 2020; Revised 12 January 2021 Accepted: 27 January 2021; Published online: 5 April 2021

\begin{abstract}
In this paper we have introduce a four switch PWM (Pulse Width Modulation) inverter for controlling the operation of PMSM (Permanent Magnet Synchronous Motor). The inverter is controlled with 49 rule base fuzzy controller controlling the current component in the feedback loop. The torque of the machine is reduced with the help of second order filter stabilizing the output from the fuzzy controller. The second order torque harmonics are produced by DC capacitor voltage fluctuations are demonstrated first, and a very simple method for compensation is presented by introducing a novel nonorthogonal coordinate transformation. The design of the three phase four switch PWM inverter is modeled in MATLAB software with all graphical representations and reports generated with dynamic characteristics.
\end{abstract}

Keywords: Pulse Width Modulation, Permanent Magnet Synchronous Motor,Inverter,Fuzzy Controller

\section{Introduction}

The Permanent magnet synchronous motors (PMSM), driven by three-stage voltage source inverters(VSI) with six switches (TPSS), have turned into the focal part of variable-recurrence drive frameworks in numerous mechanical applications as a result of their unrivaled highlights, for example, their high effectiveness and high power thickness. In any case, in specific applications, cost diminishment of the inverter arrangement is taken as the need. Consequently, the three-stage four-switch (TPFS) inverter exhibited in [1]-[11] speaks to a promising alternative for supplanting the TPSS inverters because of its lessened number of energy switches. Furthermore, the TPFS inverter can be used to ride through open/impede of the TPSS inverter, which is very important in some basic applications, for example, wind control era [7],[8]. In PMSM drives, a characteristic downside to be repressed is torque swells, which cause undesirable acoustic commotion and torsional vibrations, notwithstanding bringing about shaft disappointments [12], [13]. Thus, a few methods for the torque swell lessening are acquainted with enhance the execution of PMSM drives. In [14]-[17], the cogging torque of a PMSM is smothered utilizing motor plan methods, for example, skewing, fragmentary space pitch winding and advanced attractive outline. In [18]-[24], the throbbing torque caused by the back-EMF sounds in the PMSM is repaid by dynamic control techniques, for example, tedious control, iterative learning control and self-versatile control. Besides, as an unmistakable result of the non-sinusoidal voltages inspired by using converters, the high recurrence torque music in PMSMs are firmly affected by the received voltage vectors amid the exchanging time frame [12], [13]. Thusly, [25]-[29] use extra dynamic vectors and upgrade their span times amid the changing time frame to decrease torque swells in coordinate (DTC) torque controlled PMSM drives. Be that as it may, torque swell lessening strategies are predominantly centered around TPSS inverter-sustained PMSM drives. All things considered, some different contemplation for torque swells stay to be connected to TPFS inverter-encouraged PMSMdrives.

In any case, the capacitor voltage counterbalance concealment strategy in [6] and [7] uses a moment arrange low pass channel (LPF) to remove the DC balance segment, which is not material to TPFS inverter-nourished PMSM drives under conditions of low speed because of the decreased soundness edge of the control circle caused by the restricted data transmission of the LPF. In this way, an incresed capacitor voltage balance concealment technique material to TPFS inverter- sustained PMSM drives is required to take out the low-recurrence torque swell caused by the restricted direct regulationrange.

In this paper, the far reaching investigation of torque swell lessening is displayed as far as a three-stage fourswitch (TPFS) inverter-nourished PMSM drive, including the adjustment plot, the straight tweak extend, and an appropriate control system. The throbbing torque in the three-stage four-switch (TPFS) inverter- bolstered PMSM drive delivered by the uncompensated tweak methodologies is first shown, and a basic repaid technique is proposed to straightforwardly get the obligation proportions by presenting a novel facilitate change. At that point, the effect on the high-recurrence torque sounds of the SVM methodologies is broke down by presenting the root mean square 
(RMS) estimation of the torque swell. Furthermore, three SVM procedures for TPFS inverter-bolstered PMSM drives are scientifically assessed as far as their capacities to decrease the high-recurrence torque swells. Also, the direct balance scope of the TPFS inverter-sustained PMSM drive is completelyexploredconsideringcapacitorvoltagevacillations.Asindicatedbytheproposed examination, proper DC transport voltages under different working conditions can be effectively acquired to wipe out the low recurrence torque swell caused by finished balance. In the mean time, a versatile DC counterbalance voltage concealment technique that is appropriate for three-stage four-switch (TPFS) inverter-bolstered PMSM drives under any working condition is proposed. Thus, the DC transport voltage is completely abused to kill the low-recurrence torque swell caused by the capacitor voltage counterbalance. The test comes about demonstrate that the proposed investigation and techniques for torque swell lessening are substantial andsuccessful

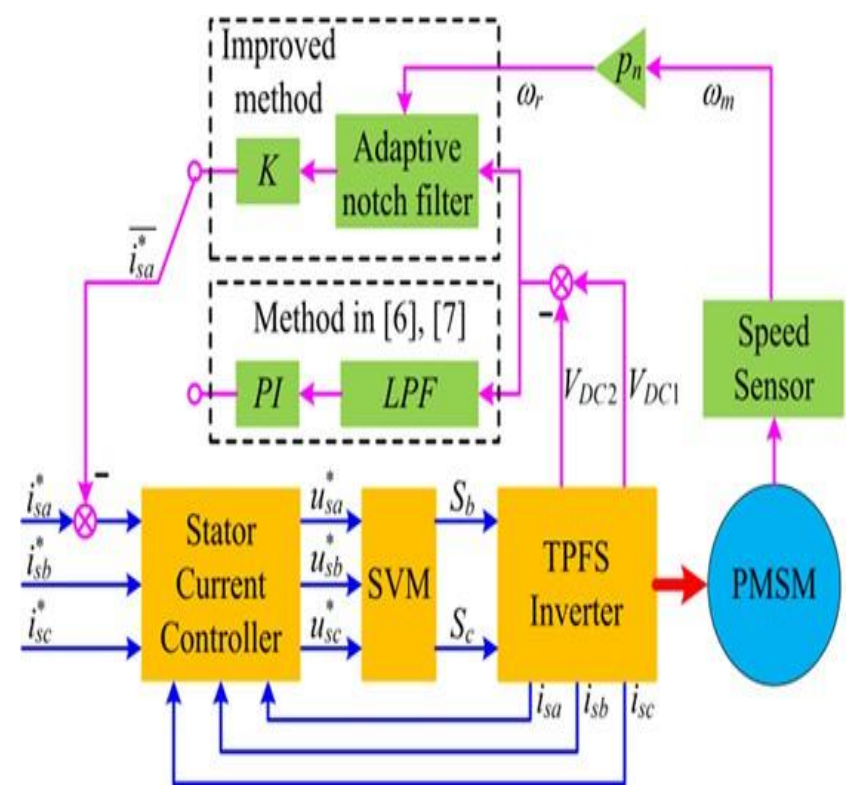

Fig:1 : Block Diagram for the PMSM motor Control Technique

\section{Fuzzy Controller Design}

Application of fuzzy controller is increasing day by day with vast electrical and electronic devices for robust operations. This controller is used for better and improved results for the operation in consumer appliances such as washing machines, micro ovens air conditioners etc., Fuzzy controller are basically used to unsharp the output boundaries with nearest value of generation for faster mode of operation. Simply defining in PI controller generates precise values narrowed to a specific point making the system to be accurate at every instant of time, whereas fuzzy controller generates a value nearer to the defined point making it more robust and instant reaction.

Fuzzy logic controller is bound to interpret words rather than numbers making it more viable for human interface with wide sense of values. The toolbox in MATLAB software generates membership functions with certain limits making it more flexible and user friendly for giving the rules with word notifications. But however words are less prices than numbers with this methodology the ruling is also made simple with output generation. Fuzzy controllers have vast applications in many devices with fuzzy rule or simple fuzzy if-then rules. The rule base is may be artificial intelligence with computer generated values with fuzzy antecedents and values. The major part of fuzzy is defining the input and output membership functions with defining the rules by human interface, however the output value generated are by artificial intelligence. I many applications the fuzzy control is a solution for controlling the system with a human translation depiction of the values. Fuzzy computation related to neuron computation and genetic algorithm computing may be represented as soft computing. As the hard computing represents more of unpredictable values which are more artificial not according to real world, where as the soft computing generates values which are more near to real world making the controller work in synchronization to the real values in bounded limits stabilizing the system with controlled saturation membership functions. The use of these real world values the changes the control structure to more robustness, tractability and also reduction in cost making the system more economic for several applications. In future as compared to traditional control techniques the fuzzy controller surpasses the problems providing optimal solutions with high machine IQ compared to conventional techniques. With a simple diagrammatic representation the fuzzy controller can be explained more easily which can be shown below. 


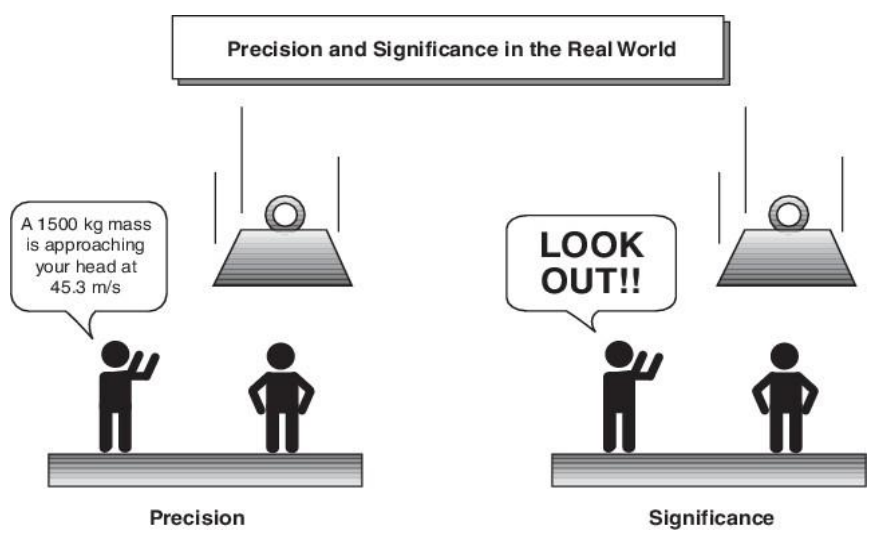

Fig. Simple representation to understand fuzzy logic

As it can be see that the figure that the representation of a mass falling on a person while the other person is warning him specifically with particular values. Due to this representation the reaction of the person becomes slow because of precise parametric notification. Whereas in the other figure the person is warning in a simple manner, making the reaction faster and get the work done. This concept of representation can be implemented in control structures to make the system react faster to any change in the reference values. For suppose considering a blower machine rotating at a certain rpm (revolutions per minute) takes reference by user defined value. When the reference value changes the with respect to user defined value, the PI controller generates a specific value representing accurate parameter generation. But, in fuzzy the change of the value is represented with a nearest value generation for immediate change in the parametric value for fast mode of operation, making the machine to react faster to the changes given by the user. This value generation is considered as mapping of input space and output space with particular set of rules. These rules which are defined by the user has starting point and ending point which are given as limit bounds where the values doesn't exceed these limits, saturating the control structure to a particular value.

\section{Applying Fuzzy Control In Some Of The Practical System}

In an automatic gear transmission automobile, the shifting of gears are done with respect to a specific limit bound values of the speed. Taking a feedback of the speed from the automobile wheel rotation the shifting of gears are done. For example to shift the gear from $2^{\text {nd }}$ to $3^{\text {rd }}$ the input space is taken from $40 \mathrm{kms} / \mathrm{sec}$ to $50 \mathrm{kms} / \mathrm{sec}$ and the output space is maintained at $3^{\text {rd }}$ limit. The output space can be limited or specifically a value. To make it simpler consider a customer feedback system in a restaurant with quality of service the restaurant on how good the place and food is. Implementing fuzzy in this feedback structure, with the given rating by a customer in a particular input space limiting values the fuzzy controller generates a rating, analyzing the inputs given by the costumer. The final result will generate a range of tip that can be given to the person making it simpler for the customers to determine thevalue.

In a camera opting automatic focusing method for taking pictures the lens adjusts the lens position by taking a feedback of the distance of the object or person. The lens adjustment is done with input space saturation limits depending on the maximum length of the capture. With a certain position of the lens in the camera the picture clarity is modified, making it easier for the user to handle the device with lesser auto adjustment time.

A representation of the fuzzy input space and output space operation can be seen below.

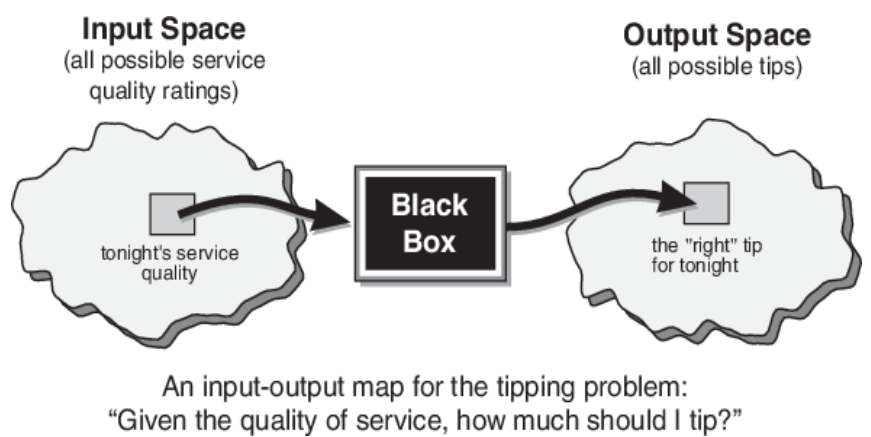

Fig. :Graphical representation of fuzzy input and output mapping 
As it can be seen in the figure that the input mapping is feedback of quality of service, and the output mapping is tip value. The black box in the middle can have linear systems or fuzzy or formulation or differential equations or look up tables or even AI (artificial Intelligence) advisor for generation of possible options at the output mappings.

\section{Advantages And Disadvantages Of Using Fuzzy Logic Controller}

\section{A. Advantages}

Fuzzy controller is a very intuitive method for reaching the goal with lesser complexity and flexible operating conditions with simple results and approach. For designing a control system with traditional approaches the modeling has to be done from initiating the input and output values from scratch. But in fuzzy the mapping of the input and output need not be done from scratch as it can be initiated with already defined values. Fuzzy itself means being imprecise as the values generated are no precise as that of other controllers. Fuzzy controller determines the values with unstable values without tacking the values and auto adjust with stabilization of the system. With further modifications on fuzzy the controller can be further modified to ANFIS (Adaptive Neuro Fuzzy Interface Structure) with non-linear operations. The output mapping value is tuned to more nearest values with more stabilization with faster response rate. A data has to be predefined with more resolution and has to be trained, adapting to the values given by the user or the feedbacks system. Fuzzy systems can be easily replaceable or act as substitute without any change in the total feedback system or even work parallel with other controllers without any disturbance or interceptions. The systems can be easily updated with fuzzy leaving the other control predefined data or user system undisturbed. Construction of fuzzy control is simple as the interface language is very simple and easy to understand. The mapping can be defined with words rather than numbers which makes it more easy to define the rules in the structure.

\section{B. Disadvantages of fuzzy controller}

Fuzzy controller is not ideal and cannot be used as a solution to any problem. Convenience of mapping the input and output spaces does not make it ideal for every application. Consider a robotic hand to place nuclear rods in a fusion tank which has to be placed in exact position. As fuzzy control doesn't give precise results the placement may be not at the exact position which results in wrong fusion reaction and may even damage the tank and some cases even the plant. So even the reaction time of the controller is more, conventional PI controllers are the solution for the above problem of placement. But as per the air blower application the speed need not to be precise, where the rpm can be set between particular ranged values with faster reaction time with change in the referencevalue.

It can be described more as a common sense than intelligence, by given an immediate result solving the problem for faster response required system which need not be precise. While some systems have to have intelligent controllers to get exact value where the reaction time is not mandatory but the value has a vital role

\section{Results}

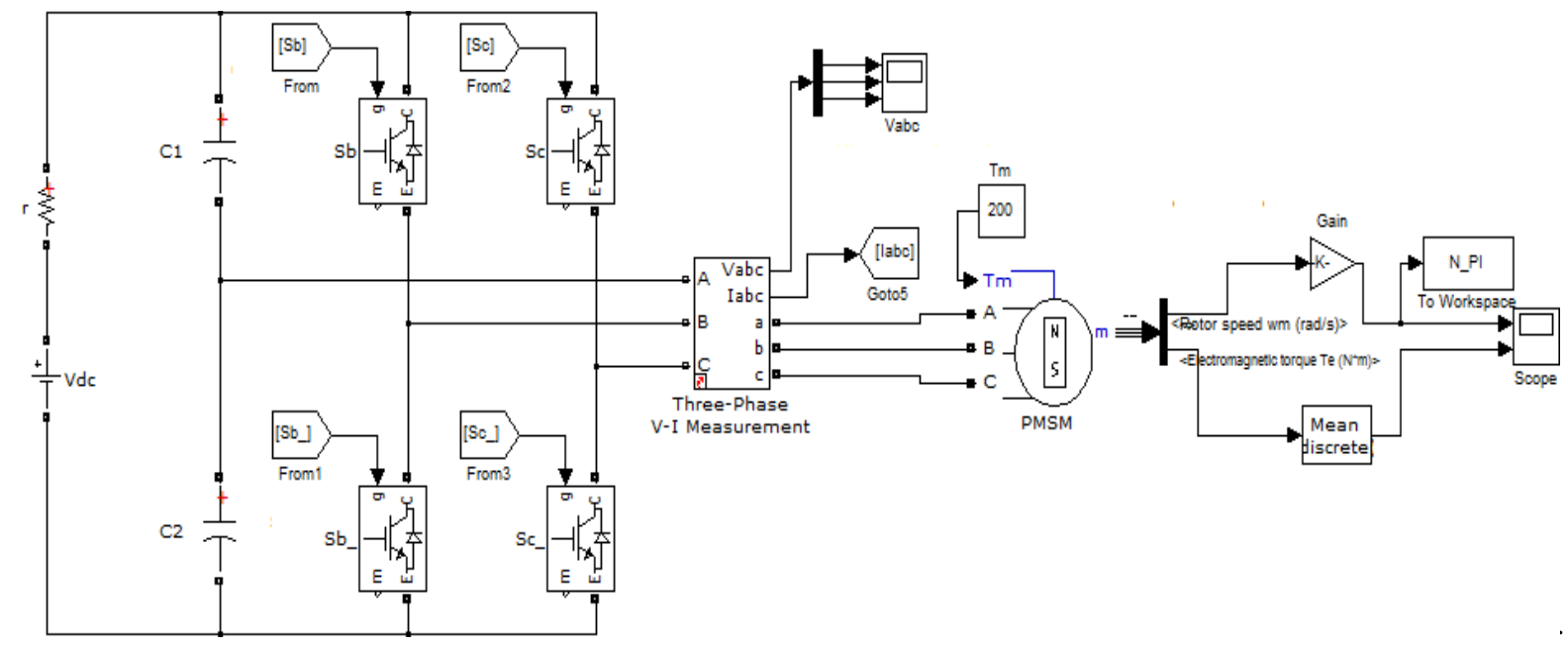

Fig:5 TPSS inverter with PMSM 


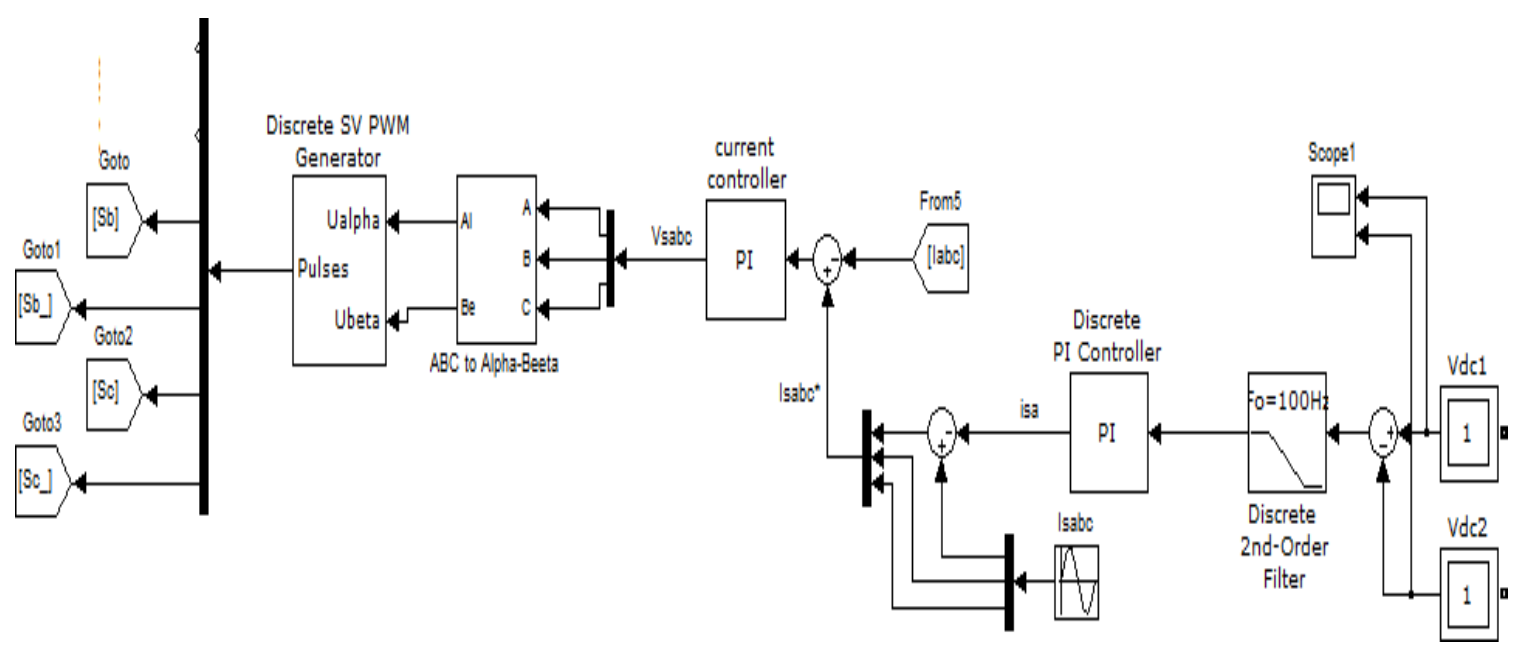

Fig:6 PI controller control structure

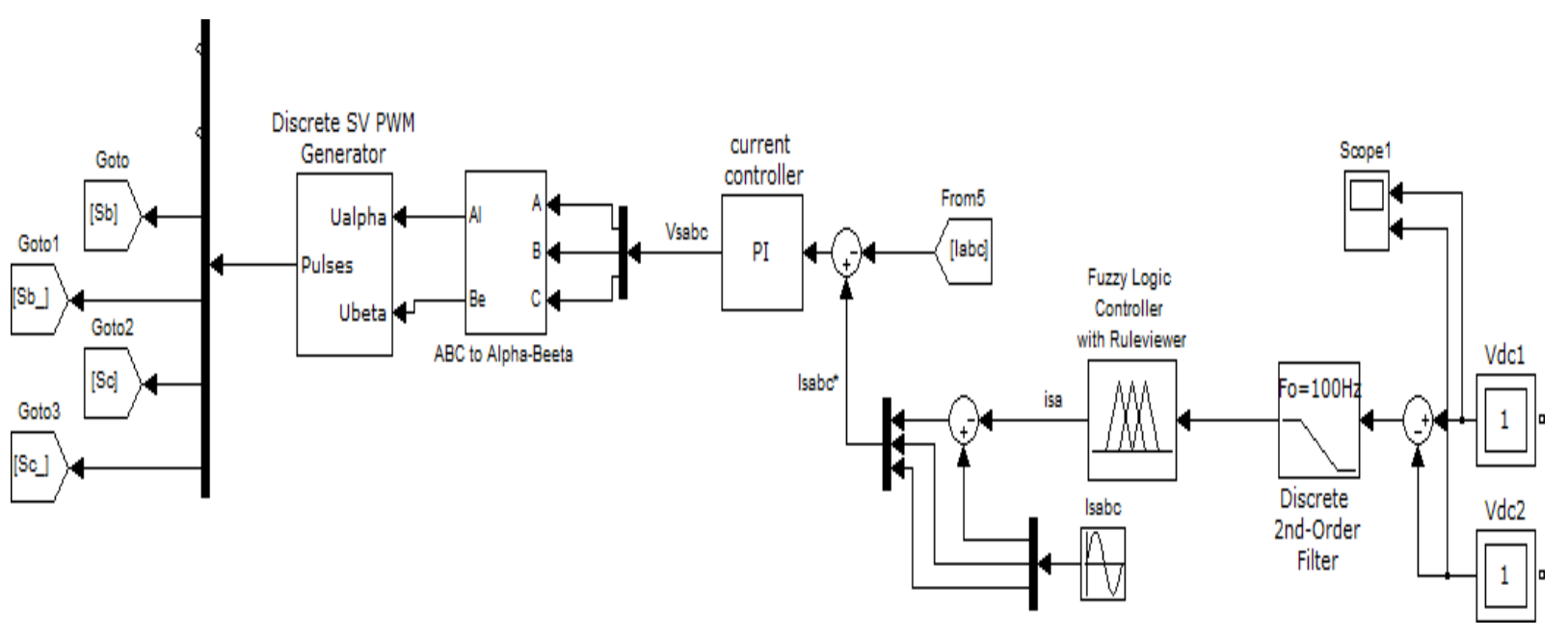

Fig:7 Fuzzy Controller control structure

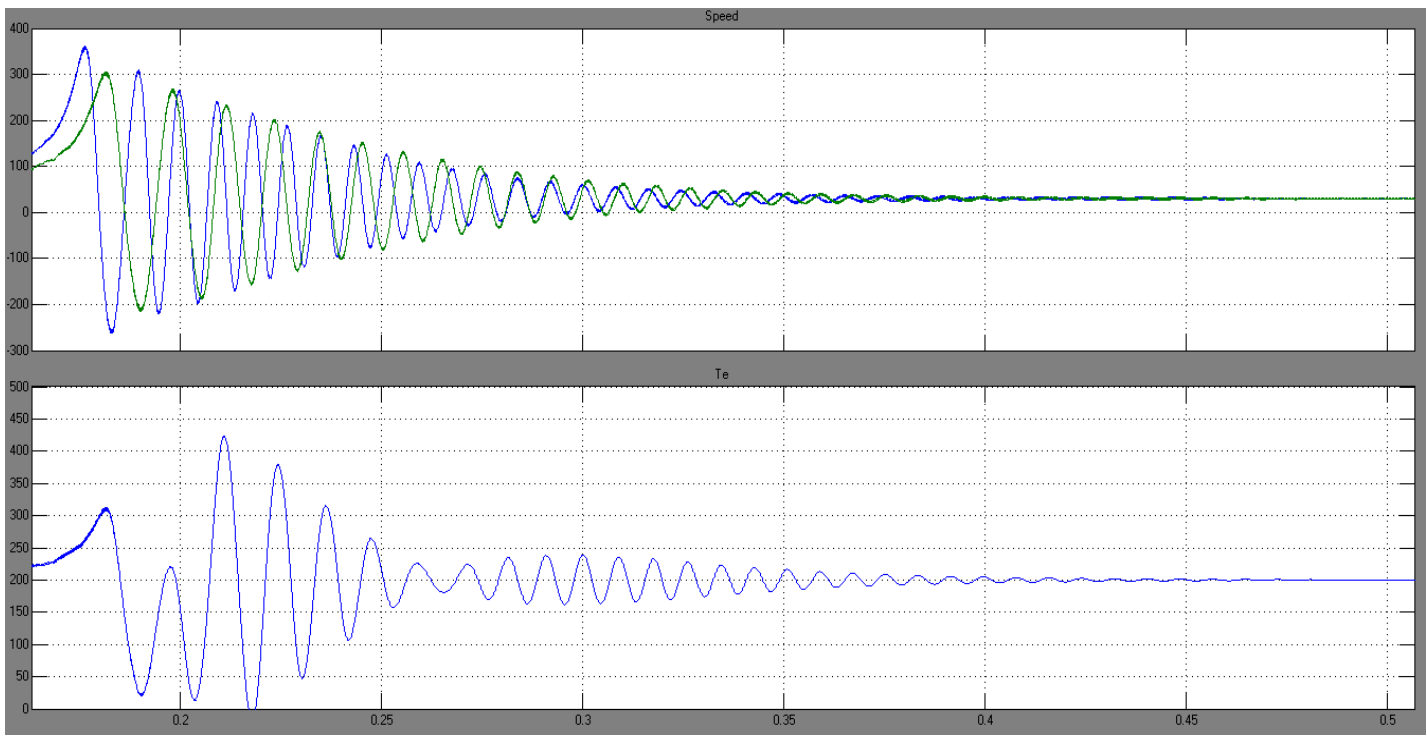

Fig: 8 Speed settling comparison with PI (Blue) and fuzzy (Green) control 


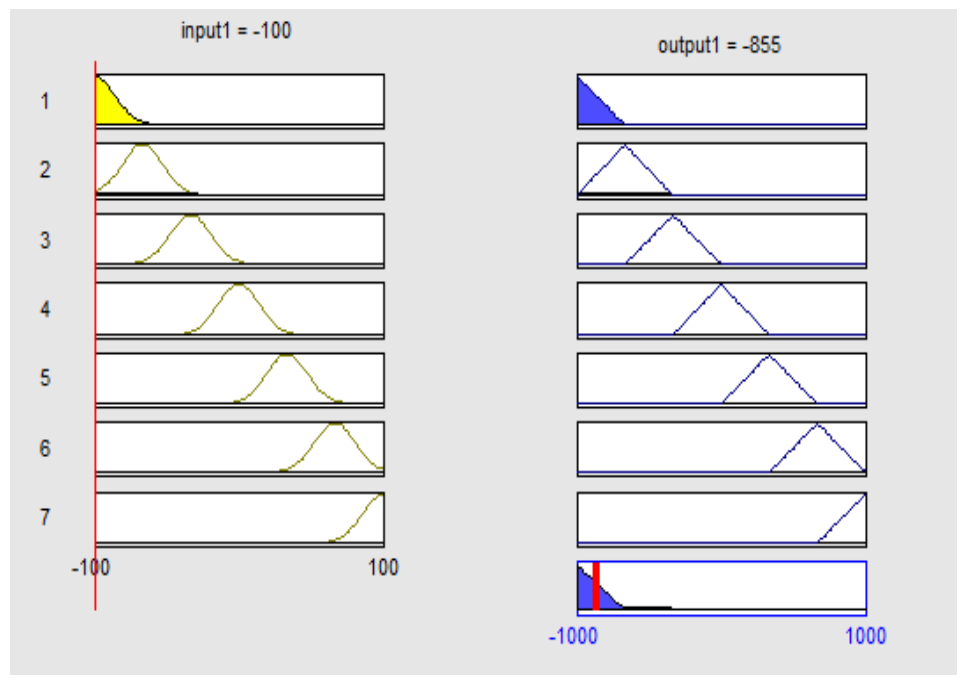

Fig:9Fuzzy Rule base

\section{Conclusions}

With the above correlation of aftereffects of the PI and fuzzy controller in the TPSS inverter control the speed of PMSM with fuzzy controller is more steady and response time is decreased. The inverter is adjusting to the change with preparing the fuzzy structure with back proliferation advancement calculation. The blunder esteems are adjusting to the dynamic difference in the voltages of the capacitors and are tuned to the TPSS inverter..

\section{References}

H. W. Van der Broeck \& J. D. Van Wyk, "A Comparative Investigation of a Three Phase Induction Machine with a Component Minimized Voltage Fed Inverter under Different Control Options," IEEE Transections. Industrial Application. Vol. IA-20, no. 2, pp. 309-320, March. 1984

K. GiTaek \& T. A. Lipo, "VSI PWM rectifier/inverter system with a reduced switch count," IEEE Transections. Ind. Appl., vol. 32, no. 6, pp. 1331-1337, November./December. 1996.

F. Blabjerg, S. Freyson, H. H. Hansen, \& S. Hansen, "A new optimized space vector modulation strategy for a component minimized voltage source inverter," IEEE Transections Power Electron., vol. 12, no. 4, pp. 704714, July. 1997.

Z. Zeng, W. Zheng, R. Zhao, C. Zhu, \& Q. Yuan, "Modeling, modulation, \& control of the three phase four switch PWM rectifier under balanced voltage," IEEE Transections Power Electron., vol. 31, no. 7, pp. 48924905, July. 2016.

Z. Zeng, W. Zheng \& R. Zhao, "Space vector based hybrid PWM strategy for reduced DC link capacitor current stress in the post-fault grid-connected three-phase rectifier," IEEE Transections Power Electron., vol. 63, no. 8, pp. 4989-5000, August. 2016.

W. Wen, L. An, X. Xiayng, F. Lu, M. C. Thuyen, \& L. Zhou, "Space vector pulse-width modulation algorithm \& DCside voltage control strategy of three-phase four switch active power filters," IET Power Electron., vol. 6, no. 1, pp. 125-135, January. 2013.

Z. Zeng, W. Zheng, R. Zhao, C. Zhu, \& Q. Yuan, "The comprehensive design \& optimization of the post fault grid connected three phase PWM rectifier," IEEE Transections Ind. Electron., vol. 63, no. 3, pp. 1629-1642, March. 2016.

N. M. A. Freire \& A. J. Marques Cardoso, "A Fault-Tolerant Direct Controlled PMSG Drive for Wind Energy Conversion Systems," IEEE Transections Ind. Electron., vol. 61, no. 2, pp. 821-834, February. 2014.

B. El Badsi, B. Bouidi \& A. Masmudi, "DTC Scheme for a Four Switch Inverter-Fed Induction Motor Emulating the Six-Switch Inverter Operation," IEEE Transections Power Electron., vol. 28, no. 7, pp. 35283538, July. 2013.

M. Masmudi, B. El Badsi \& A. Masmoudi, "DTC of B4-inverter fed BLDC motor drives with reduced torque ripple during sector-to-sector commutations," IEEE Transections Power Electron., vol. 29, no. 9, pp. 48554865, September. 2014

Z. Dehong, Z. Jin \& L. Yang, "Predictive torque control scheme for three phase four-switch inverter fed induction motor drives with dc link voltages offset suppression," IEEE Transections Power Electron., vol. 30, no. 6, pp. 3309-3318, June. 2015. 
J. Song Manelle, S. Schroder, T. Geyer, G. Ekemb, \& JM. Nyobe Yome, Prediction of mechanical shaft failures due to pulsating torques of variable-frequency drives, ॥ IEEE Transections Ind. Appl., vol. 46, no. 5, pp. 1979-1988, September./October. 2010.

X. Han \& A. B. Palazolo, VFD machinery vibration fatigue life \& multilevel inverter effect, IEEE Transections Ind. Appl., vol. 49, no. 6, pp. 2562- 2575, November./December. 2013.

G. H. Jang \& D. K. Lieu, "Vibration reduction in electric machine by magnet interlacing," IEEE Transections Magn., vol. 28, no. 5, pp. 3024-3026, September. 1992.

N. Bianchi \& S. Bolonani, "Design techniques for reducing the cogging torque in surface mounted PM motors," IEEE Transections Ind. Appl., vol. 38, no. 5, pp. 1259-1265, September./October. 2002.

R. Islam, I. Husain, A. Fardoun, \& K. McLaughlin, "Permanent magnet synchronous motor magnet designs with skewing for torque ripple \& cogging torque reduction," IEEE Transections Ind. Appl., vol. 45, no. 1, pp. 152160, Jan./February. 2009.

X. Gu, J. A. Emes, A. A. Iraolaoitia, J. J. Del Hoyo, X. Ferna, \& P. Ndez, "Torque analysis in permanent-magnet synchronous motors: a comparative study," IEEE Transections Energy Convers., vol. 26, no. 1, pp. 55-63, March. 2011.

G. Ferretti, G. A. Magnani \& P. Rocco, "Modeling, identification, \& compensation of pulsating torque in permanent magnet AC motors," IEEE Transections Ind. Electron., vol. 45, no. 6, pp. 912-920, December. 1998.

Petrovic, R. Ortega, A. M. Stankvic, \& G. Tadmor, "Design \& implementation of an adaptive controller for torque ripple minimization in PM synchronous motors," IEEE Transections Power Electron., vol. 15, no. 5, pp. 871-880, September. 2000.

B. Grcar, P. Cafta, G. Stumberger, \& A. M. Stankovic, "Control based reduction of pulsating torque for PMAC machines," IEEE Transections Energy Convers., vol. 17, no. 2, pp. 169-175, June. 2002.

Q. Wizhe, S. K. Panda \& X. JiXin, "Torque ripple minimization in PM synchronous motors using iterative learning control," IEEE Transections Power Electron., vol. 19, no. 2, pp. 272-279, March. 2004.

X. JinXin, S. K. Panda, P. YaJun, H. L. Tong, \& B. H. Lam, "A modular control scheme for PMSM speed control with pulsating torque minimization," IEEE Transections Ind. Electron., vol. 51, no. 3, pp. 526-536, June. 2004.

P. Matavelli, L. Tubina \& M. Zigliotto, "Torque-ripple reduction in PM synchronous motor drives using repetitive current control," IEEE Transections Power Electron., vol. 20, no. 6, pp. 1423-1431, November. 2005.

Muthubalaji. S., Anand. R, Senthilpandian P "Performance enhancement analysis of an isolated DC- DC converter using fuzzy logic controller" International Journal of Engineering \&Technology (UAE), ISSN 2227-524X vol.7 No 1.2 pp. 205-210 (2017) 